\title{
Wild gardening as a sustainable intensification strategy in northwest Cambodian smallholder systems
}

\author{
Sarah Eissler ${ }^{\text {* }}$ \\ The Pennsylvania State University
}

David Ader ${ }^{\mathrm{b}}$

University of Tennessee Institute of Agriculture

Sovanneary Huot ${ }^{c}$

The Pennsylvania State University

\author{
Stuart Brown ${ }^{\mathrm{d}}$ \\ The World Vegetable Center
}

\author{
Ricky Bates ${ }^{\text {e }}$ \\ The Pennsylvania State University
}

Thomas Gill ${ }^{\mathrm{f}}$

University of Tennessee Institute of Agriculture

Submitted July 16, 2020 / Revised November 13, 2020, and January 6, 2021 / Accepted January 6, 2021 /

Published online May 17, 2021

Citation: Eissler, S., Ader, D., Huot, S., Brown, S., Bates, R., \& Gill, T. (2021). Wild gardening as a sustainable intensification strategy in northwest Cambodian smallholder systems. Journal of Agriculture, Food Systems, and Community Development, 10(3), 107-126. https://doi.org/10.5304/jafscd.2021.103.006

Copyright (C 2021 by the Authors. Published by the Lyson Center for Civic Agriculture and Food Systems. Open access under CC-BY license.

\begin{abstract}
Within the last decade, Sustainable Intensification (SI) has emerged as a strategy to respond to future food security challenges. It incorporates increased food production without the cultivation of more land while incurring no net environmental cost.

a * Corresponding author: Sarah Eissler was a Ph.D. candidate at the time of research at The Pennsylvania State University.

She is now an independent consultant based in Philadelphia, PA, USA; Sarah.e.eissler@gmail.com

${ }^{\mathrm{b}}$ David Ader, Research Assistant Professor, University of Tennessee Institute of Agriculture.

c Sovanneary Huot, Ph.D. candidate, The Pennsylvania State University.

d Stuart Brown was a researcher at The World Vegetable Center in Siem Reap, Cambodia.

He is now a Research Station Leader, CSIRO Boorowa Agricultural Research Station.

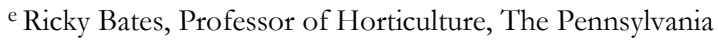
State University.

${ }^{\mathrm{f}}$ Thomas Gill, Smith Chair and Director of International Programs, University of Tennessee Institute of Agriculture.
\end{abstract}

Frameworks attempting to measure SI often focus heavily on production indicators while overlooking other important indicators, such as impacts on economic, social, or human conditions. In this study, we evaluate the purposeful assemblage and management of neglected and underutilized species (NUS) in fringe areas around rural homesteads as a potential SI strategy. We use a recent SI assessment framework developed by the Feed the Future Innovation Lab for Collaborative Research on Sustainable Intensification (SIIL) that incorporates

\section{Funding Disclosure}

This study was funded in whole or part by the United States Agency for International Development (USAID) Bureau for Resilience and Food Security/Center for Agriculture-led Growth under the Cooperative Agreement \# AID-OAA-L14-00006 as part of Feed the Future Innovation Lab for Collaborative Research on Sustainable Intensification (SIIL). Any opinions, findings, conclusions, or recommendations expressed here are those of the authors alone. This work was also supported by the Smith Center for International Sustainable Agriculture at the University of Tennessee Institute of Agriculture as well as the College of Agricultural Sciences at Penn State University. 
five measurable domains (productivity, economic, environmental, human condition, and social). We present findings from a qualitative case study in northwest Cambodia to assess local conceptualization of wild gardening, current uses of NUS, perceived benefits and challenges to their use and management, and the potential of wild gardening as a SI strategy. The qualitative methods employed 65 key informant interviews and four focus group discussions with both men and women participants. Our results indicate that wild gardening is an important component of rural livelihoods in northeast Cambodia. However, a general lack of knowledge of strategic benefits, such as nutrition potential, inhibits its use for maximum benefits. Wild gardening addresses multiple SI domains simultaneously and demonstrates the potential to be a promising SI strategy for improving rural livelihoods in Cambodia.

\section{Keywords}

Perennial Vegetables, Cambodia, Neglected and Underutilized Species (NUS), Qualitative, Sustainable Intensification

\section{Introduction}

It is estimated that by 2050 the world's growing population will require $25 \%$ to $70 \%$ more food (Hunter et al., 2017). This presents a challenge given the increased global competition for required food production resources such as land and water. Within the last decade, sustainable intensification (SI) has emerged as a strategy to address these future intersecting food security challenges. SI posits that increased food production (intensification) must play a role in meeting this food security challenge, but that this increase should come from existing agricultural land, and that the increased food production should incur no net environmental cost (sustainable) (Peterson \& Snapp, 2015; Pretty \& Bharucha, 2014, 2018; Tilman et al., 2011). For example, SI tools or practices may include selecting disease-resistant varieties that reduce the need for chemical inputs, or opting for precision farming for improved fertilizer use efficiency while simultaneously minimizing detrimental nutrient runoff or leaching.

As a strategy to sustainably increase agricul- tural production, SI holds particular promise for smallholders and the systems they manage, as these land managers, by definition, are generally already constrained by available land resources. An SI approach enables smallholders to diversify their production and income potential and enhance household food security and nutrition, while returning positive ecosystem services and environmental benefits (Mockshell \& Kamanda, 2018; Tilman et al., 2011). However, SI is not a one-size-fits-all approach. Instead, approaches to sustainably intensify a food production system should be locally adapted and fitted to address pressing food security issues within a specific geographical region.

SI is of particular interest for smallholder systems in Southeast Asia, where the average landholding is 1.0 ha (Rigg et al., 2016). Cambodia's farming system is largely composed of rain-fed paddy rice on these small landholdings. Following a single harvest, much of the landscape remains idle and without vegetative cover. Agricultural land degradation is widespread, and Cambodian household diets are among the least diversified in Southeast Asia. Many rural households confront challenges to improving their agricultural system, including a lack of resources and limited availability of and access to land (Gill et al., 2020). Additionally, low income and limited income-generating opportunities impact levels of food and nutrition insecurity. While rice-based smallholder agriculture is the primary farming system in rural Cambodia, but it may also incorporate other livelihood activities, such as livestock, wild food collection, trade, and vegetable or palm sugar production (Culas \& Tek, 2016). There is a pressing need in Cambodia to increase the diversification of agricultural systems to both improve human nutrition and restore degraded landscapes. This needs to be achieved in a sustainable manner by increasing the resilience and profitability of smallholder production and marketing systems.

As there is limited additional fertile land in this region that could be brought into agricultural production to meet rising production demands, other strategies are needed to intensify the production of these smallholder systems sustainably. While much emphasis has been placed on strategies to intensify 
traditional cropping and livestock practices, little attention has been paid to sustainably intensifying the management and use of assemblages of neglected and underutilized species (NUS) around smallholder homes, through what we term wild gardening. This qualitative study explores the potential of wild gardening as a scalable SI strategy in rural Cambodia using a recently developed SI assessment framework (Musumba et al., 2017).

\section{Wild Gardening}

Wild gardening is the intentional cultivation of a variety of NUS by smallholders for different uses across time and space. NUS are defined as possessing under-exploited potential for contributing to food security, health, income generation, and environmental services (Jaenicke \& Hoschle-Zeledon, 2006). Typically, NUS are naturally occurring wild or semidomesticated native varieties of trees, shrubs, vines, and groundcovers adapted to local environments and considered 'wild' by cultural perception (Cruz-Garcia \& Struik, 2015; GonzálezInsuasti \& Caballero, 2007). However, the term 'wild' does not necessarily imply a lack of human management; rather, these types of species are considered to lie along a management continuum from 'truly' wild (no management whatsoever) to wild-cultivated and semidomesticated species (Cruz-Garcia \& Struik, 2015; Harris, 1989).

Little attention has been paid by agricultural researchers, plant breeders, and policy-makers to NUS and their potential to enhance agricultural development outcomes (Abebe et al., 2010; Bates et al., 2013; Padulosi et al., 2002; Vogl-Lukasser et al., 2010). However, a growing body of research has examined the extent to which NUS exists in the Southeast Asian context (Cruz-Garcia \& Price, 2014a; 2014b; Cruz-Garcia \& Struik, 2015; Price, 2003; Price \& Ogle, 2008; Somnasang \& MorenoBlack, 2000). Wild gardening yields tremendous opportunities to fight poverty, hunger, food insecurity, and malnutrition, and increase resiliency of agricultural production systems to climate and environmental change (Betts \& Hawkins, 2014; Ebert, 2014). Wild gardening also offers potential for high levels of species, temporal, and spatial diversity, which helps rural households optimize their use of space around the homestead for maximum benefits (Cruz-Garcia \& Struik, 2015). These smallholder systems can be supported further to optimize these spaces by adopting a sustainable intensification approach that focuses on three primary dimensions: function, space, and time.

\section{Functional dimension}

Wild gardening is a critical and strategic source of household food, nutrition, medicine, fodder, and other livelihood resources for rural households worldwide (Cruz-Garcia \& Struik, 2015). NUS are often managed by women (Sachs, 2018). They are important sources of household food and nutrition, generally complementing rural diets and providing an array of sources for nutritional and dietary diversity by yielding essential minerals, micronutrients, vitamins, and secondary metabolites (Padulosi et al., 2013; Rowland et al., 2017). For example, Moringa oleifera is high in vitamin A and calcium; Basella alba (Malabar spinach) is high in fiber, vitamin A, C, and potassium; and turmeric (the spice from Curcuma longa) is high in magnesium, manganese, and fiber. This nutritional diversity is particularly important in Asian countries, where diets rely heavily on rice (Freedman, 2015).

NUS may also indirectly contribute to household nutrition as a source of income or livestock feed, as an integrated element in a farming system, or as a component in traditional medicinal systems (Cruz-Garcia \& Price, 2014a; Cruz-Garcia \& Struik, 2015; Freedman, 2015; Laval et al., 2011; Rowland et al., 2017). Wild gardening also serves a functional purpose in maintaining, propagating, and exchanging NUS among farmers via informal seed systems as opposed to seed sold by commercial or formal seed systems (Delang, 2006).

\section{Spatial dimension}

Wild gardening is a core component of the cultivation of a range of diverse plant species in Southeast Asia smallholder systems across multiple spaces. It is assumed to be predominantly a rural phenomenon, as urban spaces for agriculture in Cambodia are dwindling, suggesting that fringe spaces for wild gardening may also be reduced or limited in number and acreage (Underhill, 2013). Wild gardening most commonly occurs in and around home gardens in rural areas, and it is arguably one 
of the longest agricultural traditions practiced in the region (Wiersum, 2006). It also occurs in multiple 'fringe' areas, such as those along the road, at the edge of the forest, or surrounding rice paddies. Household members may gather and actively cultivate NUS in these varied spaces for household use and/or transplant NUS to their homestead to manage in wild gardens.

Smallholders frequently cultivate NUS to maximize the use of both vertical and horizontal space, particularly in land-constrained areas common to Southeast Asia. Figure 1 provides an illustrative example of using vertical and horizontal space to maximize the productive potential of the land. Wild gardening ranges from distinct spaces for gathering NUS to mixed crop gardening, interspersed with both wild plants and domesticated crop varieties. Wild gardening uses all spatial plant niches via the cultivation of a variety of plant types, including trees, shrubs, vines, and groundcovers. NUS maximize potential space use for optimal nutritional and economic benefits while also providing environmental services, such as creating favorable microclimates, improving hydrology, and increasing soil quality (Friday, Drilling, \& Gamty, 1999).

\section{Temporal dimension}

Wild gardens are particularly important for the livelihood benefits yielded during times of stress or food scarcity (Cruz-Garcia \& Price, 2014a; CruzGarcia \& Struik, 2015; Moreno-Black \& Somnasang, 2000). NUS are essential components of rural diets, as they are readily accessible and do not incur time or financial investments to maintain or use (Moreno-Black \& Somnasang, 2000). They therefore provide a low-maintenance alternative, as NUS are amenable to varying levels of management intensity and can be assembled based upon the households' goals. In rural Cambodia, NUS are usually harvested by women in varying quantities and utilized at specific times of the year for many purposes, including but not limited to consumption, sale, traditional medicine, and others. Often, NUS harvesting requires minimal labor or time inputs, which is favorable given women's existing time burdens (Asian Development Bank [ABD], 2015; Sachs, 2018; Thorng et al., 2015).

Figure 2 highlights wild gardening's role in sustainably intensifying smallholder Cambodian systems across seasons. Cambodia annually experiences one major wet season (between June and November) and one dry season (December to May). Wild gardening has the potential to provide

Figure 1. Optimizing Tropical Plant 'Layers' with Perennial NUS

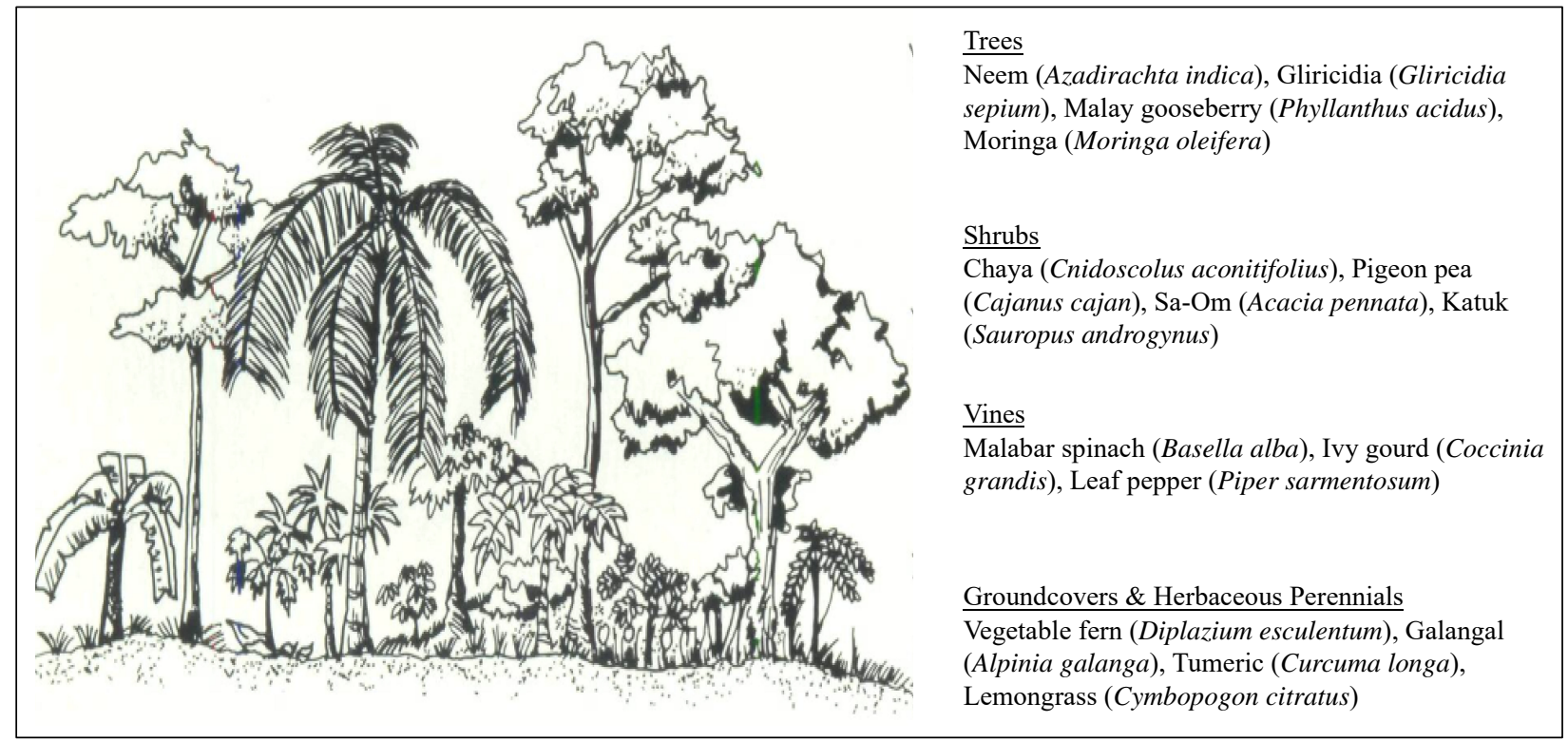

Adapted from Friday et al., 1999. 
Figure 2. Potential for Optimizing Across Temporal Food Gaps ${ }^{a}$

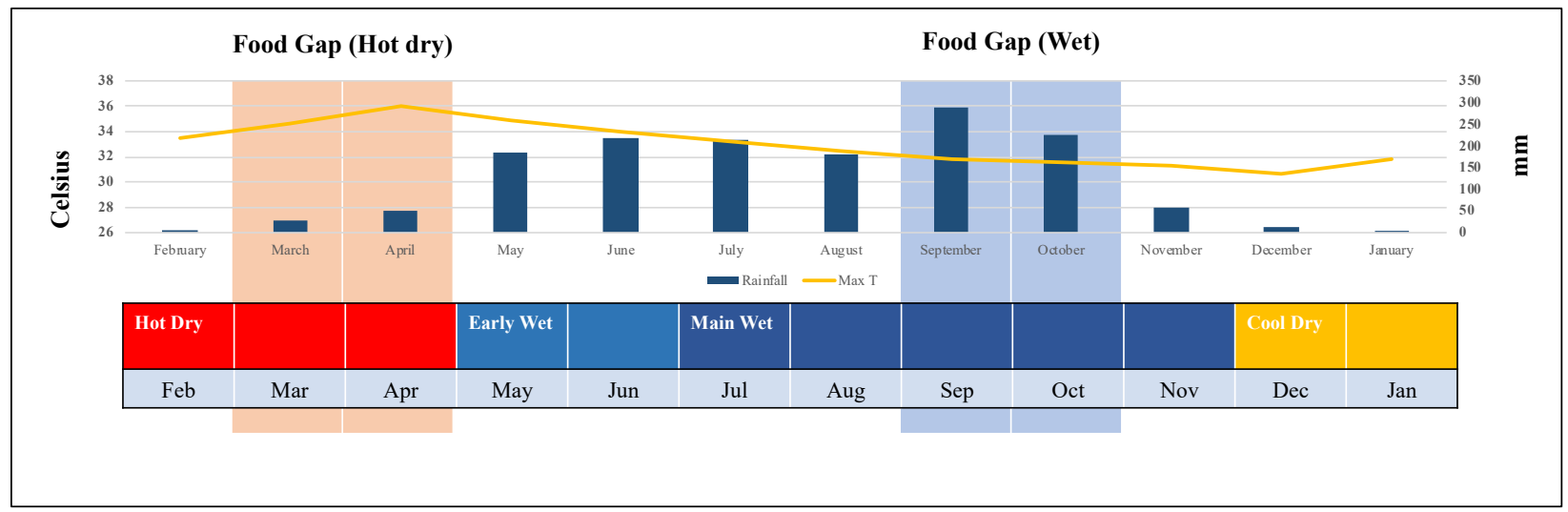

a Figure presents rainfall and temperature data from Siem Reap Province, 1998-2010.

Image Author: Stuart Brown, World Vegetable Center.

critical sources of nutrition or products for sale outside of traditional times of harvest, such as the annual rice harvest in November-December. It also has the potential to supplement household and animal diets during 'food gaps,' when other food and forage sources may be reduced in availability or accessibility. Many wild garden species, such as banana (Musa spp.), are perennial in production, allowing for year-round harvests. Some species, such as sweet potato (Ipomoea batatas), can be left in the ground and harvested over multiple months without imminent risk of loss due to biotic or abiotic stressors. Furthermore, whereas certain NUS, such as pigeon pea (Cajanus cajan) and chaya (Cnidoscolus aconitifolius), are generally well-adapted to the difficult growing conditions encountered during the two 'food gaps', other species such as moringa (Moringa oleifera) can be selectively pruned by farmers to maximize biomass production during the 'hot-dry food gap.'

\section{Conceptual Framework: Wild Gardening for SI}

Our research on wild gardening is based on the Sustainable Intensification Assessment Framework developed by the Feed the Future Innovation Lab for Collaborative Research on Sustainable Intensification (SIIL) at Kansas State University (Musumba et al., 2017). This framework presents a rigorous and comprehensive mechanism to conceptualize and measure the impact of SI packages.
It was developed through a systematic process with participants across eight institutions with diverse disciplinary perspectives. The framework also considers indicators for assessing SI across spatial scales (plot or field, household, landscape) as well as the following five domains (Musumba et al., 2017). The five broad domains include productivity, economic, environmental, human, and social. We selected this framework as a tool to assess the efficacy of new ideas and technologies in agriculture for SI because it goes beyond traditionally narrow-focused assessment indicators (such as yield per crop) by providing a holistic approach that can be expanded and refined over time (Musumba et al., 2017).

We used this framework (Musumba et al., 2017) to guide the development of the qualitative data collection tools and the qualitative analysis to evaluate wild gardening as a potential sustainable intensification strategy through a case study conducted in northwest Cambodia from December 2017 to July 2018. We purposively sampled participants in each respective data collection activity if they had managed or used NUS in the previous year around their homestead or from nearby sources. This study asked four main research questions:

- How do rural Cambodian households conceptualize and define wild gardening?

- What are the benefits to the current use and 
management of NUS in rural Cambodian households?

- What are the challenges to the current use and management of NUS in rural Cambodian households?

- What is the potential of wild gardening as an SI strategy following the SI assessment framework developed by Musumba et al. (2017)?

\section{Materials and Methods}

\section{Methods and Sampling}

This study employed multiple qualitative methods to answer the four research questions. These methods included two types of semi-structured interviews (SSI) and sex-disaggregated focus group discussions (FGD). A total of 65 men and women participated in SSIs, and 38 men and women participated in four FGDs (Table 1). This research study is part of a large research program under the SIIL that works in various rural Cambodian villages to identify and test SI technologies in the Cambodian context.

The villages selected for this particular study had been previously identified to participate in the broader SIIL research program. Participants for this study were purposively sampled from these previously identified rural villages in Battambang and Siem Reap provinces based on if they had experience with NUS (Teddlie \& Yu, 2007). Participants included households that maintained or used NUS. Wild gardening was defined to participants as using or managing plant species other than those found in vegetable gardens (or another cropping field). Both men and women within households who met these criteria were invited to participate in this study to understand the intrahousehold

Table 1. Total Number of Participants by Sex and Activity

\begin{tabular}{lccc}
\hline Activity & Male & Female & Total \\
SSI 1 & 6 & 13 & 19 \\
SSI 2 & 16 & 30 & 46 \\
FGD & 18 & 20 & 38 \\
\hline Total & 40 & 63 & 103 \\
\hline
\end{tabular}

dynamics of the maintenance and use of these wild plant species. Households were first selected; then, an able and willing adult was invited to participate in the respective data collection activity.

The FGDs were sex disaggregated. Men and women were invited to participate if they had managed or used NUS around their homestead or other nearby sources. The FGD protocols asked participants about their use and management of 27 specific NUS commonly found in Cambodia.

Two types of SSIs were conducted. The first type of SSI ('SSI 1') ( $n=19)$ asked detailed questions about specific NUS use, management, availability, and relevant benefits and challenges. These questions were open-ended; participants were asked to describe the specific NUS they utilized or maintained in their daily life. The second type of SSI ('SSI 2') ( $n=46)$ asked questions about how participants defined or conceptualized NUS, NUS maintenance and use, household gender dynamics of NUS maintenance, challenges and barriers to NUS maintenance and use, and benefits or motivations for using NUS. Table 1 presents the total sample by data collection activity and sex.

\section{Data Analysis}

The interviews were conducted in Khmer by trained Cambodian research assistants along with four authors. Data were recorded using structured notetaking sheets in the field and were then transcribed and recorded in Microsoft Excel. Native Khmer speakers fluent in English facilitated the interviews, took detailed notes of the interviews, and translated the notes into English.

The SSI data were analyzed through thematic analysis using a mix of deductive and inductive codes, guided by the five domains (economic, productivity, environmental, human condition, and social) of the Sustainable Intensification Assessment Framework (Musumba et al., 2017). Deductive codes were developed to align with indicators of each domain (presented in Table 2). Inductive codes were added to the coding framework after reviewing the qualitative data to select consistently emergent themes, such as certain types of benefits or challenges to managing and using NUS. Qualitative results are presented using direct quotes or summaries of aggregated findings. 
Table 2. Measurement Indicators Used to Assess SI Potential

\begin{tabular}{ll}
\hline Domain & Measurement Indicators Used \\
\hline Productivity & - Ability to improve household consumption \\
& - Ability to increase crop production \\
\hline Economic & - Ability to diversify production \\
& - Ability to increase income \\
& - Ability to increase diversified income save on investments \\
\hline Environmental & - Ability to save time for labor \\
& - Ability to increase species diversity [biodiversity] \\
& - Promote use of natural composts \\
\hline Human Condition & - Ability to improve access to nutrition and nutritional diversity \\
& - Ability to improve food security \\
& - Ability to improve health [medicinal] \\
\hline Social & - Gender \\
& - Social cohesion \\
\hline
\end{tabular}

contexts; this remains an important area of further inquiry.

\section{Research Ethics}

This study design and qualitative protocols were ap. proved by The Pennsylvania State University's Office of Research Protection's Institutional Review Board. All participants gave verbal consent to participate in this research study voluntarily and to be audio-recorded.

\section{Results}

\section{Local Conceptualizations of Wild Gardening \\ Consistent with the literature (Harris, 1989; Thorng, 2012),} participants conceptualized wild gardening along a management continuum rather than discrete spatial locations. Generally, participants described NUS under three main categories: cultivated (

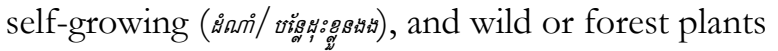

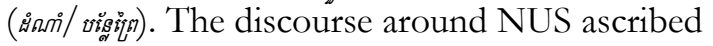
these labels. For example, one man explained that NUS are those that grow by themselves, often along homestead boundaries (the 'fringe areas'), such as along fences, roadsides, or in the rice fields or the forest, "For example, gooseberry grows by itself in the forest/bush. And the people know that those plants are edible, but with little economic value, so they do not grow them in large amount for business" [SSI, man, participant 1, 56 years old].

Some participants argued that NUS become cultivated plants once they are transplanted around the homestead. For example, a woman claimed that "galangal [Alpinia galanga] is not a wild plant. It is a transplanted plant, so it has become a cultivated plant" [SSI, woman, participant 2, 47 years old]. Similarly, another respondent pointed out that plants grown or transplanted around the home compound lose their 'wild' label, thus becoming cultivated plants. However, others maintained that these plants can still be considered wild, even if transplanted around 
the homestead. For example, one respondent clarified the difference between wild plants and cultivated plants,

Some wild plants have been collected/conserved [transplanted to the home compound] quite a long time back, but some others we haven't collected/conserved. They are still at the forest or bush. So, they are all still wild plants although they have been collected a long time ago. [SSI, man, participant 3, 36 years old]

Although participants slightly disagreed over the categorization of wild versus cultivated plants, they categorically agreed that NUS are those grown in fringe areas (of the household or rice paddy) or those gathered from the forest.

\section{Benefits of Wild Gardening}

Participants across our sample reported a range of benefits from using and maintaining NUS, presented in Figure 3.

The most commonly reported benefit of wild gardening is its use in providing sources for household consumption. One man explained,
It is important to have these wild plants around the house because when [we] need to cook some particular food that need those wild plants, especially Samlor Kakou (mixed vegetable soup). It is the traditional Khmer food that need most of wild plants. We can find them around our house. We don't need to go very far, or we don't need to spend money to buy them. And most importantly, wild food plants are chemical-free, unlike commercial vegetables and plants. [SSI, man, participant 1]

NUS are important components of rural diets in Cambodia. Traditional Khmer meals incorporate common NUS, such as ivy gourd leaf, star goose-

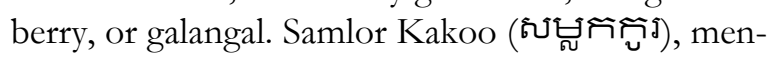
tioned by participant 1 , is a common Khmer dish, prepared as a soup that combines a variety of vegetables, herbs, and fresh fish, making it rich in nutritional diversity. Participants highlighted that wild gardening is a beneficial cost-saving strategy, as it saves them time ( $18 \%$ of sample reported) and money ( $20 \%$ of sample reported) by not having to travel to either purchase or forage for food sources. Additionally, $14 \%$ of the sample indicated that NUS are used as food for livestock and fisher-

\section{Figure 3. Reported Benefits of Wild Gardening}

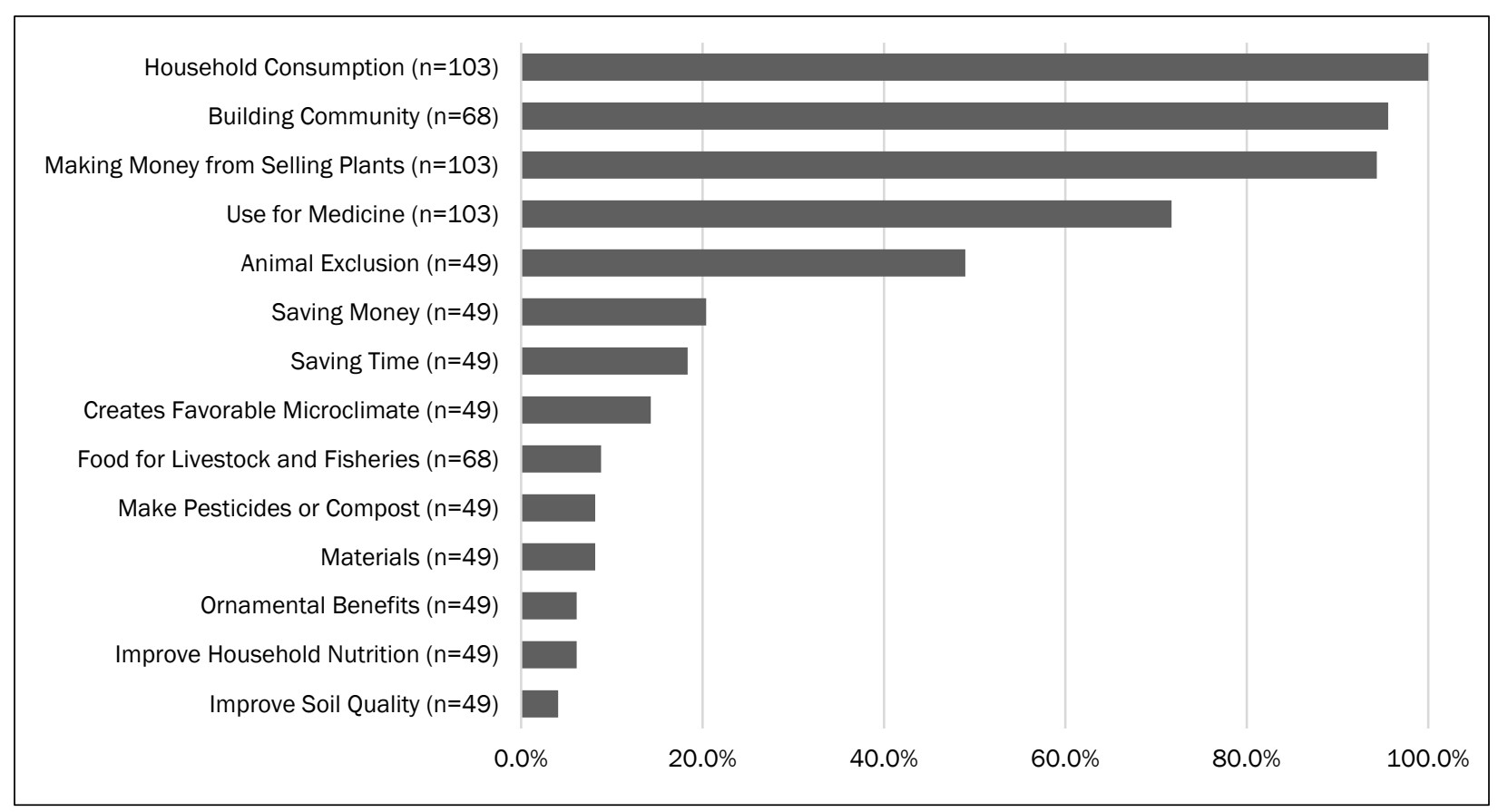


ies, providing a similar cost-saving benefit to households for their livestock rearing activities. However, while all participants cited using NUS for consumption, only $6 \%$ of the sample identified improving household nutrition as a major benefit. This difference suggests a knowledge gap for how NUS can be utilized for maximum benefits.

A majority of the participants $(96 \%$ of the sample) cited that wild gardening facilitates community building as a major benefit. For example, $85 \%$ of participants noted that they always share NUS amongst neighbors, providing an opportunity to build social capital and cohesion. Other participants reported using the benefit that NUS can yield favorable microclimates (14\%), ornamental aesthetics $(6 \%)$, or delicious fruits (1 participant) as a way to intentionally entice neighbors, family, and friends to visit their homestead.

Participants cited the income-generating opportunity from managing and using NUS as a major benefit. Ninety-four percent (94\%) of the sample cited selling NUS to traders or at the local market, generating additional and diversified income streams to support their livelihoods. Participants in the FGD agreed that they are willing to sell any of the NUS; however, there is not always market demand for certain species. Participants also indicated that the cost-saving benefits of managing and using NUS enable households to redirect cash previously reserved for food items or pesticides to other important purchases.

Some NUS are used as a means of physical protection, such as a living fence around the homestead to protect against roaming livestock or wildlife. Indeed, $49 \%$ of the sample indicated that NUS serve as a physical protection of the homestead, which not only saves the household from having to purchase materials to build a fence, but also saves the loss potential of harvest and income from grazing animals.

\section{Barriers to Wild Gardening}

All participants were asked open-ended questions about the challenges or barriers to wild gardening. Participants cited three major barriers and challenges to using, managing, and maximizing different NUS species near their homestead: lack of knowledge for how to maximize NUS potential, lack of available space and suitable soil quality to expand wild gardening areas, and lack of capital to invest in certain management practices or species.

A lack of knowledge for how to maximize benefits from wild gardening presented as a primary limitation. A majority of participants were not aware of the variety of benefits available to them via wild gardening. First, a majority of participants were not aware of the nutritional potential of NUS. For example, a majority of participants in this sample either had no knowledge of NUS nutritional potential or were aware of this potential but did not know how to harness it. One woman highlighted the latter point, explaining she knew "the plants could be used for something, like cooking for health" because she saw her neighbors cooking it, "but [she] just didn't know how" [SSI, woman, participant 4, 32]. As exceptions, two women had attended trainings at a local community health center about using NUS to increase household nutritional diversity. These women maintained a diverse wild garden and had in-depth knowledge of how to use which plants for optimal nutritional or medicinal benefits. Both women encouraged others in their community to attend trainings to improve their household nutrition and learn how to best use NUS for household nutrition.

NUS have long been a part of indigenous and traditional medicinal practices in Cambodia, and it is important to highlight the wealth of indigenous knowledge regarding the use and management of NUS. For example, these plants have been used in traditional medicines to cure some common diseases, such as stomach disorders (diarrhea and dysentery), fever and headache, skin diseases, stomach worms, snake and scorpion bites, colds, and others (Aryal et al., 2018). Much of this knowledge is passed generationally, but such knowledge transfers have been hindered by out-migration and a general erosion of cultural practices in rural communities (Inta et al., 2013; Wester \& Chuensanguansat, 1994). Seventy-two percent of participants pointed to over 30 different uses of certain NUS to cure or ameliorate certain ailments. For example, one woman shared that papaya root was used to ameliorate kidney issues; another cited using neem to treat fevers. Those who had knowledge of the medicinal benefits of NUS indicated learning these 
benefits from a training at the health center, a neighbor, or from a village medicine man (a village expert in using plants for traditional medicine). More participants $(72 \%)$ reported knowledge of the medicinal benefits of NUS than did those of potential nutritional benefits $(6 \%)$.

Secondly, $34.8 \%$ of participants cited a lack of space with suitable soil around their homestead as a major barrier to increasing the number of species incorporated around their homestead. Some participants $(n=8)$ reported not having any additional space to plant certain species around their homes. Soil quality was also considered an issue, as available soil around the homestead was of too poor quality to support additional or new NUS. For example, one woman wanted to grow Sesbania grandiflora and galangal in her wild garden, but cited having "no space available to grow [it]," and poor soil quality as inhibiting factors [SSI, woman, participant 4].

Participants cited an overall lack of capital to invest in securing seeds or cuttings. While a majority of participants $(85 \%)$ indicated that they sourced NUS (cuttings, seeds, or via other techniques like grafting) from their neighbors, some participants $(n=18)$ purchased seeds, cuttings, or plant materials at the local market, highlighting a potential lack of knowledge of the available methods to transplant NUS. Although some participants said that most plant species are shared between neighbors, others reported little sharing of germplasm between neighbors. The social dynamics of informal seed systems and sharing of germplasm require further inquiry. This finding suggests a need for greater NUS germplasm availability and perhaps an opportunity for the expanded presence of NUS in Cambodia's retail nursery industry.

\section{Wild Gardening and Sustainable Intensification} We applied the SI Assessment Framework developed by Musumba et al. (2017) to explore wild gardening as a potential SI strategy. The framework suggests several indicators to assess each of the five domains, but also accommodates flexibility for new, applicable indicators under each (Musumba et al., 2017). Table 2 presents the indicators used in this study to qualitatively assess the potential of wild gardening as an SI strategy.

\section{Productivity}

We examined how households were able to use wild gardening to increase production yields, diversify production sources, and increase sources for household consumption (Table 2). Across the sample, wild gardening directly enabled households to produce more plants for household consumption, sale (income), materials, and other uses. Wild gardening also indirectly contributed to an increase in overall household production, as households could use NUS and income generated from its production to reinvest into other crop production or multipurpose reasons, saving time and money. Twenty percent of our sample indicated a major benefit of wild gardening was saving money by using NUS to replace items (pesticides, fish and livestock feed, food products) that they otherwise would have to purchase.

Importantly, wild gardening enabled women, specifically, who generally were responsible for its maintenance, to increase production under their control. Our data do not indicate if women were then in control over the incomes generated from the sale of NUS, making this an area requiring further research. However, wild gardening enabled women, who are responsible for preparing meals, to access a variety of food plants close to home, saving time and money from having to travel to the market and purchase these items. All participants indicated using NUS, such as morning glory (Ipomoea aquatic), bamboo shoot (Bambusoideae spp.), amaranth (Amaranthus spp.), and turmeric (Curcuma longa) for household consumption.

\section{Economic}

We examined wild gardening's ability to increase household profits, diversify income streams, save capital on investments, and save time needed for labor activities (Table 2).

Over $90 \%$ of our sample indicated that they sold NUS from their wild gardens for additional sources of household income (Figure 3). One woman described the profits she gained from selling sa'oum (Acacia pennata), making upwards of US $\$ 12 /$ day for her harvest, in addition to other NUS she sold, representing a lucrative market opportunity.

Wild gardening, which can sustain and incor- 
porate a diversified assemblage of NUS, yields the potential to diversify household sources of income, as NUS provide households with diversified market options to sell their harvests. For some species, like kaffir lime (Citrus hystrix), papaya (Carica papaya), and wax gourd (Benincasa hispida), traders travel through villages to each household, pick their own harvest, and then pay the representative household member for their take. Women often manage these sales, as they typically are home when traders arrive. For other species, like water hyacinth flower (Eichhornia crassipes), water mimosa (Neptunia oleracea), and wild morning glory (Ipomoea $s p p$.), women and children pick the harvest. Then women sell it at either a local village market or a central market closer to a city, depending on market saturation. One woman explained that sa'oum has to be sold in central markets because "everyone in the village has the [sa'oum] plants, so no one will buy at [the local market]" [SSI, woman, participant $5,45]$. Other plants such as amaranth, kaffir lime, and water hyacinth flower may be sold in the village market, where sellers gain higher profits.

Additionally, wild gardening can reduce household expenditure — both time and financial—on otherwise necessary items. Approximately $20 \%$ of the sample cited saving money as a major benefit of wild gardening (Figure 3). For example, wild gardening provides food sources that complement diets, saving the household money from having to purchase these food sources at the local market. Other sources of savings cited across our sample include using NUS in mixtures as natural pesticides or organic composts $(8 \%)$, as raw materials for a fence or construction $(8 \%)$, or as fish or livestock feed $(9 \%)$. The Cambodian diet heavily relies on fish, which constitutes $80 \%$ of the country's animal protein intake, and is considered a secondary staple food to rice (McNamara, 2016). One woman explained that growing chaya (Cnidoscolus aconitifolius) enabled her to not only feed her family, but also feed her fishpond. Growing chaya saves her money from buying alternative fish feed, saves her time from having to travel to the market to purchase fish feed, and maintains healthy fish, increasing their market value and thus providing additional income to be reinvested into household needs.

Eighteen percent of participants cited that wild gardening saves households time searching for and securing necessary household products and highlighted the minimal labor investment required to maintain wild gardening. Some species naturally grew around households, while others were purposively planted. Once planted, the plants require little to no additional maintenance activities, except sometimes watering during the dry season, which took anywhere from five minutes to one hour every few days, depending on the variety and volume of species maintained around the homestead. None of the participants cited sourcing or securing water for wild gardening activities as a challenge.

\section{Environment}

We examined how wild gardening in Cambodia increased species biodiversity as well as reduced the use of chemical inputs (Table 2). Overall, the intensification of homestead wild gardening can accommodate a wide diversity of plant species across three spatial scales. For example, over 20 species were identified as used and/or maintained by participants in this case study. One man maintained a particularly biodiverse wild garden, with over 12 different species, maximizing spatial capacity around his homestead to purposively yield benefits such as increased and diversified income sources, household food and fuel sources, improved household nutrition, and positive environmental effects.

Wild gardening offers the potential to reduce the need for chemical inputs due to the increased biodiversity and natural protection (Isbell et al., 2017), as well as the raw materials it provides to make natural pesticide mixtures. For example, one woman preferred wild gardening specifically for its environmental benefits due to its biodiversity. She explained that a high level of biodiversity reduced her need to rely on chemical pesticides and helped increase available soil nutrients. She also made natural pesticides from galangal [Alpinia galanga] and lemongrass [Cymbopogon citratus] and preferred this mixture to purchasing chemicals as it "saves [ber] money and is healthier for [ber] family because [she] does not like using chemicals but needs to reduce the pests on [her] trees" [SSI, woman, participant 6, 42]. Around $8 \%$ of our sample cited using materials from WFP grown in their garden to make natural composts for their vegetable crops and rice paddies. 


\section{Human condition}

We examined whether wild gardening led to improved household nutrition, increased nutritional diversity, and improved household food security and health (Table 2).

The wide variety of plants that can be cultivated through wild gardening provides diversified and accessible sources of important nutrients for household consumption. This variety also supplements household food sources. For example, Cambodian women of reproductive age and children suffer from high rates of vitamin A deficiency, and certain common NUS, such as Moringa oleifera and Basella alba, are rich sources of vitamin A (Wieringa et al., 2016). One woman described the health and nutritional benefits of each plant maintained in her wild garden, indicating that wild plants are an "easy and beneficial way to improve [her family's] health" [SSI, woman, participant 7,35$]$. As a result, she encouraged other women to grow wild plants and use them to increase their family's nutrition. Some women perceived this activity as time-consuming, sharing that they "do not have time to maintain them and would rather buy food using money from construction jobs" [SSI, woman, participant 7]. However, to this participant, keeping a wild garden was a surmountable barrier, as wild plants take "no time" to maintain but do require small time investments upfront to learn how to use and maintain various NUS [SSI, woman, participant 7]. She found value in investing the time up front, as she improved her family's nutritional diversity and supplemented her household consumption with a variety of wild plants grown in her garden.

Second, wild gardens provide households with accessible, nutritious food plants that are particularly important during seasonal food gaps or at times of hunger when most crops are unavailable or insufficient (e.g., during times of conflict). Consuming NUS was an important survival strategy for Cambodian people during the time of the Khmer Rouge in the 1970s, when citizens were forced out of cities into the countryside. One man, a farmer and survivor of the regime, explained that,

during [the regime of] Pol Pot [the leader of the Khmer Rouge], we were provided very little rice soup. ... We were able to survive because of these wild plants. We were provided one big spoon of rice soup with only few grains of rice. These wild plants provided energy ... we had morning glory, water hyacinth, water lily. We cooked dioscorea hispida and banana root as rice and with rice. We also cooked bamboo shoot as rice and soup. We survived because of these wild plants; otherwise, we would have died. [SSI, man, participant 8,87 years old]

Wild gardening promotes household food security, as it yields accessible, diverse, and nutritious options for household consumption, particularly during acute or seasonal periods when other staple food crops are unavailable or scarce. It also promotes household health via traditional medicinal properties that NUS may yield. Over $70 \%$ of our sample cited using NUS as medicine to treat ailments such as stomachache, nausea, fever, for during and post-pregnancy support, liver and kidney problems, and as an anti-venom, among others. For example, one woman described,

Moringa is used to digest or help dissolve food.... I use it once. It has rich vitamins. ... If we don't know about a plant, we can do an experiment. I cooked and ate one portion of moringa; I found it very effective. ... It is good for those who are having difficulty in digesting. [SSI, woman, participant 9, 49 years old]

Participants also preferred NUS to products purchased in the market because NUS are perceived to be organic and safe for household consumption. Participants, in general, expressed an overall lack of trust for the perceived safety of plants sold in the market, particularly those from Thailand or Vietnam, where pesticide and chemical use is abundant (Hoi, Mol, Oosterveer, van den Brink, \& Huong, 2016). In this way, NUS are perceived to promote human health through the consumption of chemical-free plants.

Wild gardening also provides the potential for households to experiment with different techniques in intercropping, grafting, soil improvement, and others, with much lower risk than a traditional 
vegetable garden or cropping field. For example, one young farmer, who worked as a construction laborer, maintained an abundance of NUS around his homestead as a hobby for consumption and experimentation. He gave most of his surplus to his sister to sell at the market and sold little harvest to traders. He would research and experiment with NUS around his home, utilizing social media, such as Facebook and YouTube, as well as Google to generate new ideas on how to cultivate new assemblages of plants. He then would share this knowledge with other community members. He indicated that while social media was a powerful tool for increasing his knowledge, he did not feel that others knew how to maximize its potential to gain knowledge.

\section{Social}

We examined social considerations related to how NUS provided a venue for community building and social cohesion and promoted gender equality (Table 2). A majority of participants (85\%) indicated relying on neighbors for knowledge, cuttings, or seeds of NUS for their own garden. Many participants $(n=58)$ described sharing their NUS harvest with neighbors. One woman explained that "It is always good to build relationships with neighbors and share [the plants]" [SSI, woman, participant 12, 43]. Another described, "[Sharing wild plants] is also good for neighbor interaction and building relationships with neighbors" [SSI, woman, participant 10, 32]. A man explained how he uses NUS harvests to build social capital, sharing harvests with neighbors "to gain favor" with them [SSI, man, participant 11, 38].

While $85 \%$ of participants shared seeds, seedlings, and cuttings for certain NUS species, not all participants relied on neighbors or community members to access NUS or knowledge about their management or use. For example, some $(n=10)$ indicated sourcing several species from the road or rice paddy fields, either transplanting these at their home or traveling periodically to pick them. Others $(n=18)$ relied on purchasing certain species from the local market. Only four participants solely sourced their NUS from the market or stores. Additionally, not all participants cited asking their neighbors for help or knowledge about best prac- tices for the management or use of NUS. In total, six participants trusted and relied on local agricultural store owners for information about NUS. While the intergenerational transfer of knowledge was the main source of information on the use and management of NUS, some participants indicated learning from neighbors or social media. For example, one woman explained that she uses Facebook or other social media groups to learn about new NUS.

Several participants cited the favorable microclimate and ornamental benefits as attributes they would leverage from the NUS to encourage visitors to their homes. Six percent $(6 \%)$ of participants said some NUS are beautiful and increase the attractiveness of their homestead, while $15 \%$ of the sample said certain NUS encouraged family and friends to visit because of the shade and cooling they provided or fruits they yielded. For example, one man specifically maintained sapodilla [Manilkara zapota] around his house because, although it took a long time to grow, the fruits enticed family and neighbors to visit his home.

We examined the extent to which wild gardening contributed to gender equality. Consistent with the literature (Oakley \& Momsen, 2007; Sachs, 2018), wild gardening was discussed as the women's responsibility. Women make decisions about which plants to grow in the wild gardens, and importantly, which plants to use in food preparation. Women are also primarily responsible for selling NUS harvests, if they are sold, and making decisions around where and how much of these species to sell. For example, one participant indicated that selling is "women's work... only women go to the market" [SSI, man, participant 13, 29]. Wild gardening often occurs around the household and requires minimal time and labor investment to maintain, yet it provides accessible food, nutrition, and potential income sources. As such, there is potential for wild gardening to save women from having to travel to markets to purchase food or materials while providing an additional source of income, thus preventing exacerbation of women's existing time burdens (ABD, 2015). However, further research dedicated to the gender dynamics of wild gardening is required to understand this potential better. 


\section{Discussion}

\section{Wild gardening as a viable, sustainable} intensification strategy?

Wild gardening is an important component of rural livelihoods in northwest Cambodia. NUS are conceptualized along a management continuum, rather than spatially, highlighting the need to understand local perspectives when proposing which specific NUS should be included in an intensification package. Participants cited a wide range of functional benefits to wild gardening, particularly pertaining to its role in household diets, building community, and increasing income. Wild gardening is used to complement staple diets of rice, providing an array of sources of nutritional and dietary diversity, and traditional medicine for rural households. NUS are important and accessible components of rural diets, particularly during seasonal food gaps, and they simultaneously offer additional beneficial livelihood uses. The variety of livelihood uses of NUS highlight the functional diversity wild gardening offers for households to improve livelihoods and overall well-being.

Importantly, wild gardening can be an option for the rural landless who often do not have access to additional land for expansion but can maximize existing land or space to accommodate perennial NUS. Wild gardening functions as a suitable and useful SI technology that brings otherwise wasted land into purposeful production. When incorporated into marginal land, fencerows, or vacant plots, NUS, particularly perennial trees, shrubs, and vines, become a low maintenance and timeefficient technique to supplement existing food systems. Wild gardening also provides households with access to improved and diverse sources of nutrition and traditional medicine, biodiversity, favorable microclimates, and sources of necessary materials (such as wood, fish or livestock feed).

While wild gardening offers a multitude of benefits, challenges nevertheless persist with promoting its intensification and scalability. The results presented in this study suggest a general lack of knowledge regarding the multitude of benefits of wild gardening and how to intensify the practice. For example, respondents overwhelmingly cited using NUS in daily food consumption, but do not necessarily seek out NUS for their nutritional value. Approximately $32.4 \%$ of children under five years of age are stunted, and approximately $46.8 \%$ of reproductive age women in Cambodia are anemic (USAID, 2018). Considering such high rates of mal- and undernutrition in Cambodia, the need to increase nutritional knowledge and diversity is important (Fiorentino et al., 2016).

The intensification of NUS via knowledge sharing between neighbors within a community offers a promising alternative to addressing this need, as these NUS are already readily consumed. Additionally, while the physical ownership of horizontal space around a homestead may pose a potentially limiting factor for increasing diversification of wild gardens, vertical levels of space (Figure 1) can be further intensified to include different varieties of NUS. Thus, knowledge gaps hinder the use of NUS for their maximum potential; strategies to intensify wild gardening should focus on addressing these gaps.

Aligned with Musumba et al.'s (2017) assessment framework, we used several indicators to explore the potential of wild gardening under each respective domain for smallholder systems in northwest Cambodia (Table 2). Cultivating NUS increases household food production (productivity), provides the potential for diverse incomes streams (economic), reduces the need for purchasing and using chemical inputs (environment and economic), provides an accessible source of diverse nutrition (human condition), and facilitates community building and social cohesion (social). The functional diversity of NUS and wild gardening enables benefits to cut across several domains. For example, using NUS for making natural composts contributes to both environmental and economic domains as it saves households money and time from procuring inputs, and reduces the overall need for use of chemical inputs.

In rural Cambodian households, wild gardening is an existing, albeit uncommon, practice that merits greater attention. Wild gardening holds the potential to provide a high level of sustainability and greater resilience to a low-input food system, complementing home vegetable gardens with a much less resource-intensive food production strategy. NUS and wild gardening yield several 
positive impacts for rural households, from increasing access to nutritional sources and income streams to saving money. Thus, there is ample opportunity to scale this strategy in Cambodia and in other regions where wild gardening is already practiced. Whereas results of this study demonstrate that Cambodian smallholder farmers value these various aspects of wild gardening and NUS, a number of significant challenges remain if this SI technology is to see a wider regional impact. For one, NUS are part of an informal seed system with limited access to germplasm for some perennial species.

We also find that the cultivation and use of NUS are embedded in indigenous knowledge, such as their use in traditional medicines (Aryal et al., 2018). With less intergenerational transfer of knowledge and rural and youth out-migration from agriculture, these knowledge systems are eroding. Furthermore, NUS knowledge is not included as part of the Cambodian formal Agricultural Education and Training curriculum. These constraints may pose limitations to the efficacy of scaling a wild gardening SI strategy across Cambodia and therefore require further research to understand how they can be overcome.

\section{Considering Gender when Assessing Strategies for SI Potential}

We find that certain indicators of the SI assessment framework cross-cut domains, which we present as a critique. Most notably, the social domain includes an indicator on gender; however, there are important gendered aspects to be considered across all five domains that hold implications for the viability of a successful SI strategy. For example, women play important roles in gathering and transplanting NUS to diversify family food sources (productivity) as well as in managing household food security and nutrition (human condition). Transplanting and domesticating NUS with the annual vegetables creates biodiverse and multifunctional ecosystems, which may reduce the need for chemical substances while increasing climate resilience (environment). Moreover, women may generate their own income sources by selling NUS products (economic).

In the framework, we argue that gender should be considered across and within each domain rather than as a sole indicator. Incorporating gender-sensitive indicators across domains allows for more in-depth analysis and enables broader impacts to be captured. For one illustrative example, under 'productivity,' this study corroborates the literature in that women are predominately responsible for managing household production, management, and use of NUS (Freedman, 2015; Sachs, 2018). It would be essential to understand if and how such a SI strategy aimed at scaling up NUS production would shift women's time allocation and, if so, what tradeoffs women and men would need to make to accommodate such a shift (ABD, 2015). Therefore, under the 'productivity' domain, it would be important to include an indicator on gender to understand how the SI strategy's attempt at increasing production affects current and future demands on women's and men's current and future labor and time allocation. This framework, and those similar, should ensure to incorporate gender-sensitive indicators across all domains measuring a potential SI strategy.

This approach also allows for gender considerations to be integrated into the design and delivery of SI packages (Komatsu et al., 2018; Kristjanson et al., 2017; Theriault et al., 2017). Feminist literature has long documented how men and women experience and shape social norms that form gendered opportunities and barriers, and how these may vary across geographic contexts and social identities (Alkire et al., 2013; Boserup, 1970; Meinzen-Dick et al., 2011). For example, Theriault et al. (2017) found that women plot managers were less likely to adopt an SI technology aimed to improve cereal productivity because they had significantly less access to adequate resources, such as credit, equipment, labor, and extension services, than did men, who were more likely to adopt and benefit from the technology.

Given women's role in ensuring household food security (Quisumbing et al., 2014), it is important that developers of SI packages integrate gender considerations into the design and delivery and engage with gender specialists in this process. When designing strategy packages, these gendered opportunities and barriers must be thoughtfully considered to understand those that exist for men 
and women in adopting, employing, and benefiting from such a package. We suggest that further research explore and examine the manner in which gender should be incorporated into the frameworks assessing SI strategy potential, package development, and scaling approaches.

\section{Further Research}

This study presents findings from qualitative research on how rural households in Cambodia currently use NUS, but further research is required to quantify these attributes to best package NUS suggestions for sustainably intensifying wild gardening. For example, nutritional analyses can point to which NUS are appropriate for combating acute vitamin deficiencies prevalent in certain parts of rural Cambodia (Fiorentino et al., 2016). Additional research should examine the market potential of certain NUS to target better those with higher market potential in certain contexts over others. Further effort is also needed to assess the value of wild gardening and the value-added products prepared using the harvest. Determining the influence of NUS cultivation, harvest, storage, preparation, and processing methods will enable appropriate recommendations to be made on how to gain maximum value to ensure delivery of food and nutritional security. Current efforts to understand, improve, and disseminate an intensified wild gardening system in Cambodia are limited (Thorng, 2012).

Furthermore, all future research should be situated in terms of gender relations within the household and the community to identify men's and women's roles related to NUS management and use. This will be useful for understanding decisionmaking and negotiating roles for NUS management and use, and in understanding who controls benefits from various NUS usages (see Alkire et al., 2013, and Meinzen-Dick et al., 2012, as frameworks to guide such future research).

The work presented here documents the wideranging value of wild gardens to Cambodian farmers. However, additional research is needed to illustrate how NUS integrate with and complement other components of home and community food production. This research should include documentation of quantifiable nutritional, medicinal, and economic contributions of wild gardens to rural Cambodian households as well as to other contexts. Questions worthy of attention in the context of an era of sustainable intensification include:

- What are the quantifiable potential nutritional, medicinal, and economic contributions of wild gardens to rural households?

- What role do women play in managing and maintaining NUS within wild gardens, and how would a wild garden intensification package present tradeoffs to women's time and control over resources?

- Would over-management of NUS result in a reduction of the natural biological capacity of these spaces to regenerate?

\section{Conclusion}

SI and food security remain a major development concern and an important area for research and conceptual development. While NUS are given some recognition, especially as famine foods and crises-relief foods, their role and contribution have largely remained undervalued in the food security discussion. Conservation of horticultural genetic resources has been cited as a global research priority (USAID, 2005); however, characterization of how these diverse species integrate (both individually and as wild gardens) with local food systems in specific geographic regions has been lacking.

The research presented here shows a wide range of values associated with NUS that compose wild gardens. Wild gardens mimic natural ecosystems and provide a high level of sustainability and climate change resilience as a low-input food system that complements home vegetable gardens. They are far less resource-intensive and pose less risk to farmers and can positively impact household nutrition and additional income streams. NUS are generally not traded commercially in formal markets, and as such, are insulated from regional competition compared to traditional vegetables that are cheaply imported from neighboring countries. And as such, wild gardening presents a potential positive strategy to improve rural livelihoods and overall well-being. 


\section{Acknowledgments}

The authors would like to acknowledge all research participants who shared their time and knowledge throughout the data collection process. We would also like to acknowledge the Kansas State University Sustainable Intensification Innovation Lab (SIIL).

\section{References}

Abebe, T., Wiersum, K. F., \& Bongers, F. (2010). Spatial and temporal variation in crop diversity in agroforestry homegardens of southern Ethiopia. Agroforestry Systems, 78, 309-322. https://doi.org/10.1007/s10457-009-9246-6

Alkire, S., Meinzen-Dick, R., Peterman, A., Quisumbing, A., Seymour, G., \& Vaz, A. (2013). The women's empowerment in agriculture index. World Development, 52, 71-91. https://doi.org/10.1016/i.worlddev.2013.06.007

Aryal, K. P., Poudel, S., Chaudhary, R. P., Chettri, N., Chaudhary, P., Ning, W., \& Kotru, R. (2018). Diversity and use of wild and non-cultivated edible plants in the Western Himalaya. Journal of Ethnobiology and Ethnomedicine, 14(1), 10. https://doi.org/10.1186/s13002-018-0211-1

Asian Development Bank [ABD]. (2015). Balancing the burden? Desk review of women's time poverty and infrastructure in Asia and the Pacific. https://www.adb.org/publications/balancing-burden-womens-time-poverty-and-infrastructure

Bates, R., Gill, T., Bicksler, A., Meitzner-Yoder, L., Burnette, R., \& Ricciardi, V. (2013). Designing strategies and systems to identify, preserve and promote underutilized indigenous crop species. ISHS Acta Horticulturae, 979, 569-576. https://doi.org/10.17660/ActaHortic.2013.979.61

Betts, R. A., \& Hawkins, E. (2014). Climate projections. In M. Jackson, B. Ford-Lloyd, \& M. Parry (Eds.), Plant genetic resources and climate change (pp. 38-60). CABI. https://doi.org/10.1079/9781780641973.0038

Boserup, E. (1970). Woman's role in economic development. St. Martin's Press.

Cruz-Garcia, G. S., \& Price, L. L. (2014a). Gathering of wild food plants in anthropogenic environments across the seasons: Implications for poor and vulnerable farm households. Ecology of Food and Nutrition, 53(4), 363-389. https://doi.org/10.1080/03670244.2013.808631

Cruz-Garcia, G. S., \& Price, L. L. (2014b). Human-induced movement of wild food plant biodiversity across farming systems is essential to ensure their availability. Journal of Ethnobiology, 34(1), 68-83. https://doi.org/10.2993/0278-0771-34.1.68

Cruz-Garcia, G.S., \& Struik, P. C. (2015). Spatial and seasonal diversity of wild food plants in home gardens of northeast Thailand. Economic Botany, 69(2), 99-113. https://doi.org/10.1007/s12231-015-9309-8

Culas, R. J., \& Tek, K. (2016). Food security in Cambodia: Trends and policy objectives. International Journal of Development Issues, 15(3), 306-327. https://doi.org/10.1108/IJDI-06-2016-0033

Delang, C. O. (2006). Not just minor forest products: The economic rationale for the consumption of wild food plants by subsistence farmers. Ecological Economics, 59(1), 64-73. https://doi.org/10.1016/j.ecolecon.2005.10.006

Ebert, A. W. (2014). Potential of underutilized traditional vegetables and legume crops to contribute to food and nutritional security, income and more sustainable production systems. Sustainability, 6(1), 319-335.

https://doi.org/10.3390/su6010319

Fiorentino, M., Sophonneary, P., Laillou, A., Whitney, S., de Groot, R., Perignon, M., Kuong, K., Berger, J., \& Wieringa, F. T. (2016). Current MUAC cut-offs to screen for acute malnutrition need to be adapted to gender and age: The example of Cambodia. PLoS ONE, 11(2), e0146442. https://doi.org/10.1371/journal.pone.0146442

Freedman, R. L. (2015). Indigenous wild food plants in home gardens: Improving health and income-with the assistance of agricultural extension. International Journal of Agricultural Extension, 3(1), 63-71. https://esciencepress.net/journals/index.php/IJAE

Friday, K. S., Drilling, M. E., \& Gamty, D. P. (1999). Imperata grassland rehabilitation using agroforestry and assisted natural regeneration. International Centre for Research in Agroforestry, Southeast Asian Regional Research Programme.

Gill, T., Ader, D., Srean, P., Hok, L., Cheat, S., \& Lear, A. (2020). Living fences for improved smallholder livestock systems in Cambodia. Forests, Trees and Livelihoods, 29(4), 260-277. https://doi.org/10.1080/14728028.2020.1827049

González-Insuasti, M. S., \& Caballero, J. (2007). Managing plant resources: How intensive can it be? Human Ecology, 35(3), 303-314. https://doi.org/10.1007/s10745-006-9063-8 
Harris, D. R. (1989). The evolutionary continuum of people-plant interactions. In D.R. Harris \& G.C. Hillman (Eds.), Foraging and farming: The evolution of plant exploitation. Unwin Hyman. https:/ www.worldagroforestry.org

Hoi, P. V., Mol, A. P. J., Oosterveer, P., van den Brink, P. J., \& Huong, P. T. M. (2016). Pesticide use in Vietnamese vegetable production: A 10-year study. International Journal of Agricultural Sustainability, 14(3), 325-338. https://doi.org/10.1080/14735903.2015.1134395

Hunter, M. C., Smith, R. G., Schipanski, M. E., Atwood, L. W., \& Mortensen, D. A. (2017). Agriculture in 2050: Recalibrating targets for sustainable intensification. BioScience, 67(4), 386-391. https://doi.org/10.1093/biosci/bix010

Inta, A., Trisonthi, P., \& Trisonthi, C. (2013). Analysis of traditional knowledge in medicinal plants used by Yuan in Thailand. Journal of Ethnopharmacology, 149(1), 344-351. https://doi.org/10.1016/j.jep.2013.06.047

Isbell, F., Adler, P. R., Eisenhauer, N., Fornara, D., Kimmel, K., Kremen, C., Letourneau, D. K., Liebman, M., Polley, H. W, Quijas, S., \& Scherer-Lorenzen, M. (2017). Benefits of increasing plant diversity in sustainable agroecosystems. Journal of Ecology, 105(4), 871-879. https://doi.org/10.1111/1365-2745.12789

Jaenicke, H., \& Hoschle-Zeledon, I. (2006). Strategic framework for underutilized plant species research and development, with special reference to Asia and the Pacific, and to Sub-Saharan Africa. International Centre for Underutilized Crops, Colombo, Sri Lanka \& Global Facilitation Unit for Underutilized Species. https://www.bioversityinternational.org

Komatsu, H., Malapit, H. J. L. \& Theis, S. (2018). Does women's time in domestic work and agriculture affect women's and children's dietary diversity? Evidence from Bangladesh, Nepal, Cambodia, Ghana, and Mozambique. Food Policy, 79, 256-270. https://doi.org/10.1016/j.foodpol.2018.07.002

Kristjanson, P., Bryan, E., Bernier, Q., Twyman, J., Meinzen-Dick, R., Kieran, C., ... \& Doss, C. (2017). Addressing gender in agricultural research for development in the face of a changing climate: Where are we and where should we be going? International Journal of Agricultural Sustainability, 15(5), 482-500.

https://doi.org/10.1080/14735903.2017.1336411

Laval, P., Rakotoarison, H., Savajol, N., \& Vanny, T. (2011). The contribution of wild medicinal plants towards poverty alleviation and health improvements: A case study in two villages in Mondulkiri Province, Cambodia. Cambodian Journal of Natural History, 1, 23-28. https://www.fauna-flora.org

McNamara, K. (2016). Cambodia landscape analysis: Integrating gender and nutrition within agricultural extension services. USAID Feed the Future. http://ingenaes.illinois.edu

Meinzen-Dick, R. S., Johnson, N., Quisumbing, A. R., Njuki, J., Behrman, J. A., Rubin, D., Peterman, A., \& Waithanji, E. (2011). Gender, assets, and agricultural development programs: A conceptual framework (CAPRi Working Paper No. 99). https://doi.org/10.2499/CAPRiWP99

Mockshell, J., \& Kamanda, J. (2018). Beyond the agroecological and sustainable agricultural intensification debate: Is blended sustainability the way forward? International Journal of Agricultural Sustainability, 16(2), 127-149. https://doi.org/10.1080/14735903.2018.1448047

Moreno-Black, G., \& Somnasang, P. (2000). In times of plenty and times of scarcity: Non- domesticated food in northeastern Thailand. Ecology of Food and Nutrition, 38(6), 563-586. https://doi.org/10.1080/03670244.2000.9991597

Musumba, M., Grabowski, P. P., Palm, C., \& Snapp, S. (2017). Guide for the sustainable intensification assessment framework. https://doi.org/10.13140/RG.2.2.13048.75521

Oakley, E., \& Momsen, J. H. (2007). Women and seed management: A study of two villages in Bangladesh. Singapore Journal of Tropical Geography, 28(1), 90-106. https://doi.org/10.1111/j.1467-9493.2006.00278.x

Padulosi, S., Hodgkin, T., Williams, J. T., \& Haq, N. (2002). Underutilized crops: Trends, challenges and opportunities in the $21^{\text {st }}$ century. In J.M.M. Engels, V. Ramanatha Rao, A. H. D. Brown, \& M.T. Jackson (Eds), Managing plant genetic diversity (pp. 323-338). CABI. https://doi.org/10.1079/9780851995229.0323

Padulosi, S., Thompson, J., \& Rudebjer, P. (2013). Fighting poverty, hunger and malnutrition with neglected and underutilized species (NUS): Needs, challenges and the way forward. Retrieved from the Bioversity International website: https://www.bioversityinternational.org/e-library/publications/detail/fighting-poverty-hunger-and-malnutritionwith-neglected-and-underutilized-species/ 
Petersen, B., \& Snapp, S. (2015). What is sustainable intensification? Views from experts. Land Use Policy, 46, 1-10. https://doi.org/10.1016/i.landusepol.2015.02.002

Pretty, J., \& Bharucha, Z. P. (2014). Sustainable intensification in agricultural systems. Annals of Botany, 114(8), 1571-1596. https://doi.org/10.1093/aob/mcu205

Pretty, J., \& Bharucha, Z. P. (2018). Sustainable intensification of agriculture: Greening the world's food economy. Routledge. https://doi.org/10.4324/9781138638044

Price, L. L. (2003). Farm women's rights and roles in wild plant food gathering and management in north-east Thailand. In P. L. Howard (Ed.), Women and plants: Gender relations in biodiversity management and conservation (pp. 101-114). Zed Books.

Price, L. L., \& Ogle, B. M. (2008). Gathered indigenous vegetables in mainland Southeast Asia: A gender asset. In B. P. Resurreccion \& R. Elmhirst (Eds.), Gender and natural resource management: Livelihoods, mobility and interventions (pp. 213-242). Earthscan.

Quisumbing, A. R., Meinzen-Dick, R., Raney, T. L., Croppenstedt, A., Behrman, J. A., \& Peterman, A. (Eds). (2014). Closing the knowledge gap on gender in agriculture. Springer. https://doi.org/10.1007/978-94-017-8616-4_1

Rigg, J., Salamanca, A., \& Thompson, E. C. (2016). The puzzle of East and Southeast Asia's persistent smallholder. Journal of Rural Studies, 43, 118-133. https://doi.org/10.1016/j.jrurstud.2015.11.003

Rowland, D., Ickowitz, A., Powell, B., Nasi, R., \& Sunderland, T. (2017). Forest foods and healthy diets: Quantifying the contributions. Environmental Conservation, 44(2), 102-114. https://doi.org/10.1017/S0376892916000151

Sachs, C. (2018). Women farmers and food justice: Preserving biodiversity through farmer control of seeds. Retrieved from Rosa Luxemburg Stiftung New York Office website: https://rosalux.nyc/wp-content/uploads/2021/02/RLS-NYC_womerfarmersandfoodjustice_en.pdf

Somnasang, P., \& Moreno-Black, G. (2000). Knowing, gathering and eating: Knowledge and attitudes about wild food in an Asian village in northeastern Thailand. Journal of Ethnobiology, 20(2), 197-216.

Teddlie, C., \& Yu, F. (2007). Mixed methods sampling: A typology with examples. Journal of Mixed Methods Research, 1(1), 77-100. https://doi.org/10.1177/1558689806292430

Theirault, V., Smale, M., \& Haider, H. (2017). How does gender affect sustainable intensification of cereal production in the West African Sahel? Evidence from Burkina Faso. World Development, 92, 177-191. https://doi.org/10.1016/j.worlddev.2016.12.003

Thorng, R. (2012). Identification and documentation of underutilized crops in Mondulkiri province with emphasis on socio-economic aspects (Research Working Paper No. 2). Retrieved from Mekong Institute website: https://www.mekonginstitute.org

Thorng, R., Makara, O., Vaughan, D. A., \& Vathany, T. (2015). Roles of wild food plants in Ethnic group communities in Mondulkiri province, northeastern Cambodia. Journal of Mekong Societies, 11(2), 1-17. https://so03.tci-thaijo.org/index.php/mekongjournal/article/view/38729

Tilman, D., Balzer, C., Hill, J., \& Befort, B. L. (2011). Global food demand and the sustainable intensification of agriculture. Proceedings of the National Academy of Sciences, 108(50), 20260-20264. https://doi.org/10.1073/pnas.1116437108

Underhill, S. (2013). Urban and peri-urban agriculture in Phnom Peng, Cambodia: Challenges and opportunities. Asian Journal of Agriculture and Development, 10(2), 1-14. http://purl.umn.edu/199415

USAID. (2005). Global horticulture assessment. https://pdf.usaid.gov/pdf docs/pnadh769.pdf

USAID. (2018). Cambodia: Nutrition profile. https://www.usaid.gov/sites/default/files/documents/1864/Cambodia-Nutrition-Profile-Mar2018-508.pdf

Vogl-Lukasser, B., Vogl, C. R., Gütler, M., \& Heckler, S. (2010). Plant species with spontaneous reproduction in home gardens in eastern Tyrol (Austria): Perception and management by women farmers. Ethnobotany Research and Applications, 8, 1-15. https://doi.org/10.17348/era.8.0.1-15

Wester, L. L., \& Chuensanguansat, D. (1994). Adoption and abandonment of Southeast Asian food plants. Journal of Home and Consumer Horticulture, 1(2-3), 83-92. https://doi.org/10.1300/J280v01n02 05 
Wieringa, F. T., Sophonneary, P., Whitney, S., Mao, B., Berger, J., Conkle, J., Dijkhuizen, M. A., \& Laillou, A. (2016). Low prevalence of iron and vitamin A deficiency among Cambodian women of reproductive age. Nutrients, 8(4), 197. https://doi.org/10.3390/nu8040197

Wiersum, K.F. (2006). Diversity and change in homegarden cultivation in Indonesia. In B.M. Kumar \& P.K.R. Nair (Eds.), Tropical homegardens: A time-tested example of sustainable agroforestry (pp. 13-24). Springer.

https://doi.org/10.1007/978-1-4020-4948-4_2 